\title{
HERRERA Y CERVANTES FRENTE AL MITO DE ÍCARO EN LA POESÍA CANCIONERIL
}

\section{(Dos notas sobre la poética herreriana y un contrapunto cervantino)}

José Manuel TRABADO CABADO

Universidad de León

ABSTRACT

The aim of this paper is the study of the device used by Herrera in order to introduce the myth of Icarus within the usual verse pattems of the cancioneril tradition, in which the use of mythology is most uncommon. To make this inuroduction possible, Herrera deftly manipulales several elements of XV century poetry such as boldness, fire, death, the lover identified with light, etc, which, added to the experience of Italian Petrarchists, allow him to make a series of allusions to the myth of the bold young man. With this, we try to show a link between the poetry of lialian influence and the Castilian poetic tradition. Finally, the comparison of Herrera's texts with a poem from La Galatea provides a meaningful epilogue for a contrast of attitudes and procedures.

Palabras clave Herrera, Cervantes, poesía cancioneril, İcaro.

"no tendrá culpa amor, sino su locura" (Cervantes, La Galatea)

\section{ÓRBITA CANCIONERIL.}

Todo indica que en tomo al siglo XI hubo un cambio de indole afectiva que, junto con una serie de factores circundantes, hizo cristalizar en Provenza una nueva forma de concebir el amor. Este amor fue denominado "fin' amors" o, más modernamente, "amor cortés". El fenómeno de esta nueva sentimentalidad es complejo. Tanto sus origenes como su esencia han sido ampliamente discutidos'.

Brasas de este furgo que constituia la nueva concepción del amor incendiaron los versos de los poetas cancioneriles castellanos del siglo $\mathrm{XV}^{2}$.

'Sobre los origenes las hipótesis van desde una explicación sociológica (C. S. Lewis, 1988) hasta aquellas que intentan mostrar las conexiones con la herejta cátara (Denis de Rougemont, 1984) pasando por aquellas que ven un inllujo arabe en los origenes del amor contes. Véase la bibliografia al respecto en Riquer $(1983,22$, nota 6 ). Un repaso a distintas teorias lo hace Nicasio Salvador (1977,8-10). Sobre su carácter más o menos camal también se ha debatido c incluso se ha llegado a soluciones eclécticas como la de René Nejli según recuerda Markale $(1987,47)$. Ya en el ámbito espanol la polémica se estableció entre Parker (1986) y K. Whinon (1981)

${ }^{2}$ lo cieno es que, desde el último tercio del siglo XIV hasta el fin del reinado de los Reyes Catblicos, conoce Castilla un amplio brote lírico que se recoge, esencialmente, en cancioneros colectivos, cuyas notas rememoran, en parte, las de la antigua poesla provenzal hasta el punto de 
Una de las características del amor cortés pasaba por ver las relaciones que se establecian entre amante y amada como paralelas a las que se entablaban entre siervo y señor. Opera una suerte de trasvase del código social al amoroso ${ }^{3}$. La obediencia que a la amada se debe es pareja a la obligada para con un señor feudal (Otis H. Green,1969,1,95-96; C.S. Lewis, 1988,2). Esto explica que términos como "vasallaje, homenaje, obediencia" sean moneda común dentro de los cancioneros castellanos del XV.

Por otra parte, el amante se ve rendido por la belleza de la amada que es concebida como el culmen de la perfección, la creación de Dios (Nicasio Salvador, 1977, 271-272; María Rosa Lida, 1984a, 179-290):

\title{
¿Quál señora fizo Dios
}

tan perfetta como vos...? (Santillana, 1982,66)

La belleza de la amada llega incluso a ser parangonada en su exotismo al Ave Fénix":

\author{
"Como el fenis fizo Dios \\ en el mundo sola un ave, \\ asi quiso que entre nos \\ sola tal fuéssedes vos \\ de fermosura la llave." (Mena, 1989,19)
}

Esta belleza llega a veces a cristalizar en una imagen esplendorosa y entonces la amada llega a identificarse con la fuente de la luz:

No es umana la lumbre

que de vuestra faz procede; (M. de Santillana, 1982,100)

habersele aplicado el nombre de poesia cortesana, hablándose, en consecuencia, del amor cont's que tate en la misma" (Nicasio Salvador Miguel, 1977.10)

${ }^{3}$ El uso del Iéxico propio de las relaciones feudales en la poesia amatoria de los trovadores provenzales es estudiado petfectamente por Martin de Riquer en el cápitulo de Los Trovadores. Historia y lextos titulado "pocsía fetudal" (1983,1,77-96). "De mème que le chevalier est lié par serment du un seigneur qui est plus puissant que lui, il [c] amante] doit étre le vassal d une dame et obéir au mème sement de fidelité. L'objigation d'aimer su-dessus de son rang est parallele a lobligation féodale de servir un seigneur plus élevé pour ce derrier de le protéger et de le secourir en cas de besoin." (J. Markale, 1987,42). También Nicasio Salvador dedica unas páginas a la concepción del servicio de amor dentro de la poesta cancioneril castellana $y$, más en concreto, al Cancionero de Estủniga (1977,281-284).

${ }^{4}$ Por lo que respecta a la imagen del Ave Fénix en la poesía cancioneril afima P. Manero (1991,295): "las manifestaciones que presenta la imagen abarcan varias posibilidades que pudieramos dividir, por una parte, en la representación directa, por via del relato, de uno o de varios aspectos del mito prescntado por los bestiarios con la correspondiente descripción omamental de la imagen; por otra, la elaboración indirecta (como imago a exemplum), fruto ya de una comparación o translatio, con la confrontación de un referente (...) $)^{n}$. La imagen de Mena pertenece a esie segundo grupo como asl lo hacer notar csta estudiosa $(1991,297-299)$ 
Dicha lumbre puede trocarse en hoguera en la que el poeta desea consumirse en afán de destrucción y posesión ${ }^{6}$ :

Astil de perlas preciosas
nominante diadema,
fogueras bivas, raviosas,
do mi persona se quema,
quando vuestra se formó
imagen bella, garrida,
entonçe se ordenó

la muerte para mi vida. (Mena, 1989,15)

La vista era el sentido capaz de captar toda la belleza de la amada. No en vano Capellanus, en su tratado acerca del amor, le otorga una especial importancia en el proceso del enamoramiento ${ }^{7}$. Hasta tal punto es lógico en su razonar que niega a los ciegos la capacidad de enamorarse. A esto hay que sumar la importancia de la luz en la Edad Media que se identificaba con la belleza (Bruyne, 1987,78-85). Los poetas del dolce stil nuovo no tuvieron reparos en comparar la belleza de sus amadas al sol. Así lo hace Guinizelli:

Ben si pò tener alta quanto vòle, ché la plu bella donna è che si trove, ed infra l'altre par lucente sole

e falle disparer a tutte prove. (E. Savona, 1973,153)

Para los poetas del dolce stil nuovo la luz, y con ella el amor, se comunica por los ojos, de igual manera que los spiriti que tan en boga puso Cavalcanti ${ }^{B}$. De igual manera P. Le Gentil ha destacado el papel que los ojos junto con el corazón cumplen en la poesía cancioneril $(1981,171-179)$

'Esta misma composición fa transcribe Foulché-Delbosc $(1915,11,476$ b) con autoría de lohan de Tapia. Ambas versiones presentan leves diferencias Iéxicas, atribuibles en ocasiones a lecturas posiblemernic entóneas, caso de "maguer que mi muerte vea" (lohan de Tapia) "muger, que mi muerte vea" (M. de Santillana). En otra ocasión hay una diferencia léxica "nin la fija de Pompeo" (1. Tapia) frente a "non la fija de Peneo" (M. de Santillana). En todo caso, lo que más llana la alención es la ausencia de una estrofa fla numero $V$ en la composición de Santillana- que no aparece en la de Tapia.

${ }^{6}$ Cassas Rigall (1995,73-74) mucstra ejemplos de incendios por amor en la poesía cancioneril.

${ }^{T_{\text {}}}$ Esta pasión innata procede pues de la visión y de la rélexión" (Capellanus, 1985,57)

Antonio Prieto pone en relación la obra de Francisca de Figueroa con la de Cavalcanti a propósito de los spiriti $(1984,246$ y ss.). Herrera da una amplia definición en sus enditos comentarios a la obra de Garcilaso de lo que son los spirisi (Gallego Morel1,1972,335-336) 
llegando a ser considerados traidores que hacen posible la toma del castillo alegórico que es el amante, caso de Manrique ${ }^{9}$.

Ante la imposibilidad de declarar con palabras la belleza de la amada, el poeta no ha tenido más remedio que recurrir a la comparación. Estamos ante la insuficiencia del lenguaje. Los trovadores asi lo entendieron y echaron mano del arsenal poético que se les ofrecía a través de la comparación que ponia en contacto elementos de la naturaleza con las excelencias de la amada. En este sentido fue corriente la comparación de la mujer con el sol que pasó tambièn al dominio petrarquista (Pilar Manero, 1990, 539-547) y que ocasionó toda una red metafórica perfectamente codificiada y transmitida a lo largo del XV1. Será en el XVII cuando los poetas reinterpretarán toda esa imagineria heredada dándole un impulso vital al escorzo de signo intelectualista propio del Manierismo.

Dicho está que los ojos son canal propicio para el amor y a modo de colofón de las palabras preliminares quiero traer a colación los siguientes versos donde mirada y fuego se combinan en binomio harto conocido:

Non pienses que por morir

te desquiero,

que tampoco mi bivir

sin poderte bien servir

non lo quiero;

mas fazes mi mal ravioso

ser tamaño,

que con fuego peligroso

mis ojos sin más reparo

amen daño. (Mena, 1989,31)

Llegados a este punto, a poco que se medite sobre ello, se llega a vislumbrar un estado que propiciará el inicio de una tensión. Por una parte nos encontramos que el poeta debe acatar obediencia a la dama como si fuera su sefior. Por otro lado, las excelencias de la belleza de la mujer a la que se ama reclaman su ponderación. Sin embargo, las leyes del código del amor cortés exigían el secreto (Aurora Egido,1990, 56-84). De un lado estamos ante el deseo del amante por enarbolar su pasión amorosa y, de otro, la razón avisa al poeta del estatus más elevado de la amada y exhorta a mantener su dolencia amorosa en secreto. La lucha entre el querer y el

${ }^{9}$ Mis ojos fueron traidores: / ellos fueron consintientes, / ellos fueron causadores / que entrassen aquestas gentes, / que el atalaya tenlan / y nunca dixeron nada / de la batalla que vian / nì hizieron ahumada." (1988,23-24). Acerca de la metáfora lumínica en la pocsía carsioneril, véase J. Casas Rigall (1995,75) 
temor, entre pasión y razón está servida. Es sobre esta dialéctica que se articulan no pocos versos de los cancioneros:
Alli fue la gran cuistión
entre el querer y temor,
cada cual con su razón
esforçando la passión
y alterando la color. (Manrique,1988,5)

Cualquiera de las dos salidas posibles al conflicto será causa de un "desgarrón afectivo" en palabras de Dámaso Alonso a propósito de Quevedo. Si la opción es callarse, silencio expresado paradójicamente en la publicación escrita de la pena, el resultado será dolor:

Yo callé males sufriendo

y sufri penas callando, (Manrique,1988,62)

llegando incluso a temer, en progresivo exacerbamiento de su pasión, a alcanzar la muerte:

Callé por mucho temor;

temo, por mucho callar,

que la vida perderé. (Manrique,1988,64)

$\mathrm{Si}$, por contra, la senda elegida es la de declarar el amor, rompiendo así el precepto que obliga al silencio, daremos con la figura del poeta osado que se deshace en canto dolorido:

Grande fue el atrevimiento

que cobré con el deseo,

y mayor, el pensamiento

de cuitas en que me veo:

quanto fue más atrevido

por amores,

tanto soy más afligido

de dolores. (Mena, 1989,24)

El resultado de estas dos fuerzas contrarias se fragua en la poética guerra interior del vate enamorado y temeroso a la vez:

...esta fuerte pelea

que yo comigo peleo. (Manrique,1988,65)

Asi pues, se reclama el único remedio posible para acabar con el sufrimiento que pasa por invocar a la muerte:

No tardes, muerte, que muero;

ven, porque biva contigo;

quiéreme, pues que te quiero,

que con tu venida espero 
no tener guerra comigo. (Manrique, 1988,78)

Muerte que, a mi juicio, supone la resolución de la dialéctica "osadia/temor" establecida en el interior del poeta como la resultante originada de la "cuistión" entre la belleza de la amada y el silencio impuesto al amante.

La amada se halla en una posición superior y es esta posición social la que, trasladada al lenguaje poético, se transfigura en una escala de amor alegórica que el poeta debe escalar para acercarse a su amada. En cierta manera podría hablarse de una situación embrionaria que permite pensar en mitos como los de Ícaro:

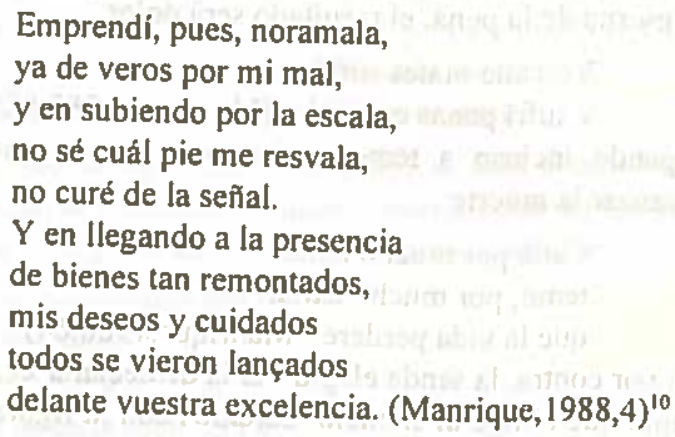

\section{LA ÓRBITA PETRARQUISTA.}

No ajena a esta guerra fue el movimiento petrarquista y ahí está Petrarca con su "Pace non trovo, et non ò da far guerra" (Canzoniere, 1989, CXXXIV). Sin embargo, fueron otros poetas seguidores de la huella de Petrarca los que decidieron solucionar esta lucha de contrarios. La solución por la que se decantan es la osadia. Para representarla poéticamente los poetas italianos bucearon en los compendios mitológicos y encontraron una figura que encajaba a las mil maravillas a la hora de representar su temeraria empresa: Ícaro, joven impetuoso que en su ansia de remontar el vuelo acaba por caer al mar. El pensamiento amoroso que se eleva en busca de la amada", las alas del deseo que remontan al amante y la consecución de la fama por parte de Ícaro al caer en el mar fueron factores decisivos para la integración de este mito en la poesía como paradigma del amante osado. No

${ }^{10}$ Señala Tumer $(1977,47)$ otro ejemplo de Manrique que dice estar próximo a la semántica del mito de ĺcaro. En esos versos el amante es un nuevo Lucier que cae ante la osadia de quererse
igualar al Amor, su Seinor.

"Petrarea ya usó la imagen de volar con ta alas del pensamiento en el Cameoniere: "Volo con I'ali de pensicri al cielo" (1989,CCCLXII) 
habia ocurrido esto con los poetas cancioneriles. Su uso de la mitologia tenla un algo de erudición, pero esa erudición actuaba más a modo de corteza que recubría la esencia poética que como parte integrante de dicha esencia ${ }^{12}$. Esto es lo que consiguen los petrarquistas, imbuidos como estaban en una corriente humanista. Asumen el mito porque se identifican con él y su empresa necesita de la magnificación del parangón de un mito clásico que elevan a paradigma que perpetúa la tradición. El primero según Turner (1977,50-68) fue J. Sannazaro con el soneto que comienza "Icaro cadde qui: quesie onde il sanmo". Lo que atrae a Sannazaro, como buen renacentista, es la idea de la fama que Ícaro consigue con su caida. Posteriormente, el citado critico aduce ejemplos de Ariosto en los que el poeta es comparado con İcaro en su intento de describir la belleza de su amada y, por fin, el poetaÍcaro es un amante atrevido: "Nel mio pensier che cosi veggio audace" (Turner, 1977,51).

De la lectura somera de los poetas que sigujeron la huella de Petrarca se desprende que es en el cauce petrarquista donde el mito de Ícaro pasa a formar parte de un sistema iconológico mucho más amplio. Se relaciona con el motivo de la mariposa que arde en el fuego, con el Ave Fénix y llega a sufrir contaminaciones con el mito de Faetón debido a su proximidad argumental. Los ojos de la amada serán soles (Pilar Manero, 1990,495-510) en los que el poeta pretende abrasarse. A todo ello hay también que sumar las doctrinas del neoplatonismo que encumbraron la luz y el sentido de la vista.

\section{HERRRERA Y LA POESÍA CANCIONERIL.}

Se ha visto cómo cuando la poesía petrarquista dio salida al conflicto pasión/razón (osadia/temor) por la vía de la osadia adoptó para ello el mito de Ícaro. Obraron desde una tradición poética en que la comparación de la amada con la luz y la osadia al declarar los sentimientos venian ya

${ }^{12}$ Con motivo del uso de la mitologia en el Cancionero de Estiñiga escribe Nicasio Salvador: "buscan los poetas hacer gala de una enudición, de una sensación de saber que, atun siendo, en muchos casos, efectista $e$ inmadura les confiere un prestigio o aureola de sabiduria. Ast, es corriente que estas ineneiones no tengan una significación precisa ni indiquen ninguna asimilación de los atutores clásicos, ( ) aunque no falten ocasiones en que las citas (..) responden, si no a un intimo conocer, al menos a un deseo sincero de aproximación. Tales referencias conllevan tambièn, a veces. un móvił didáctico pues se mira a la antigaldad como a un espejo y a sus personajes como terminos dignos de imitación." (1977,325-326). Con eslas palabras se refiere Maria Rosa Lida al uso de la mitologia que hace Juan de Mena: "Lo peculiar de Mena, premrenacentista, es qui junto a la alusión y enumeración ejemplares, ttpicas del didactismo inedieval, introduce sistemáticamente la alusión mitológica con sentido omamental que antes se halla sólo esporádicamente" (1984, 529-530). 
acuñados. Supieron ver el valor plástico que la mitología les ofrecia. La tradición cancioneril castellana agotaba su retórica en derivaciones y juegos verbales de alambicada semántica que nos transportaban a la caverna dolorida del interior del poeta.

Sin embargo, Herrera escribia ya desde la perspectiva que propiciaba la reflexión sobre el fenómeno poético. No es extraño que un hombre de tan amplia formación humanfstica y de temperamento poético tan singular diera a la luz en 1580 los eruditos comentarios sobre la poesía de Garcilaso. Reflexión y práctica poética se aunan en sus Anotaciones pero también en su obra poética. Esta reflexión es la que otorga el carácter intelectualista, rasgo caracterizador, según la crítica, del Manierismo.

En 1582 publica Herrera parte de sus poemas bajo el título de Algunas abras. Su soneto prologal recuerda, según Cristóbal Cuevas, al tipo de sonetos prologales que se derivan de una tradición iniciada por Petrarca con su primer soneto del Canzoniere ${ }^{13}$. El primer verso del soneto herreriano reza "Osé y temi, mas pudo la osadía". Argumenta el citado editor de Herrera que, a diferencia de Petrarca, el divino sevillano lo escribe cuando aún no ha superado la pasión amorosa y sigue todavía impelido por ella. No hay un proceso retrospectivo de lo que ha constituido su caminar errante de enamorado peregrino, ni tampoco se atisba el error de "los verdes affos". Herrera persigue todavía su "furor". Esto, aunado a la ausencia de poemas "in morte", nos hacen pensar en una suerte de Cancionero que se está haciendo, que no ha concluido todavia (Herrera, 1985,30$)^{14}$. Lo que quiere $C$. Cuevas resaltar (Herrera, 1985,31) es la distribución de la poesía que fluctúa entre la osadia y el temor. Volvemos, una vez más, a encontramos con el binomio que vertebra gran número de sus poemas de corte cancioneril. Sin

${ }^{13}$ La estructura de cancionero petrarquista en la antologia de 1582 es estudiada por A. Prieto (1987, 570-585) quien observa el descuidado orden en las composiciones de Herrera publicadas por Pachecho en 1619. Ello le hace pensar en una ordenación dispuesta no tanto por el propio Herrera cotno por su editor Pacheco: "Fijemonos, por ejemplo, en el soneto 'Ose, i temf, mas pudo la osadla", que abre el conjunto de Algunas, y que tiene aqut una situación inicial clara en su función de soneto-prólogo que nos introduce en unt his/oria amorosa. En Versos, este soneto aparece totalmente desplazado en el libro III, con el número XXVIII, y entre sonetos que responden a otros momentos desligados de un proceso secuencial. (...) Estos desplazamientos (desorganización) no puedo pensarlos en Herrera salvo que en su postrer etapa se sintieca tan defraudado de su intento de un cancionero que decidiera diseminas su proceso esparciéndolo como poesía amorosa sin ilación narrativa." (1987,568)

${ }^{14}$ De esbozo de un corpus poetico mós amplio habla A. Prieto al referirse a Algunas de 1582 $(1987,565)$. 
embargo, Herrera no publicó ninguno de sus poemas de corte cancioneril en la antologla de $1582^{15}$.

Se había observado cómo la amada se situaba en una posición más elevada que el poeta en la poesla cancioneril. Esto provoca que en el sistema poético herretiano se origine un impulso ascensional que irá encarnado por el deseo que emprende el vuelo como tjempo atrás lo habla hecho el pensamiento en Petrarca:

\section{Desesperado desseo \\ leuanta mi flaco buelo, $\mathrm{y}$ aunque su pérdida veo, pretendo llegar al cielo. (Herrera, 1985, 157)}

La alusión al mito de İcaro es patente tal y como indican los editores del sevillano. El poeta se afana en seguir su pasión y no cuida del engaño cierto. No estamos lejos del esplritu que vertebra el resto de sus composiciones italianizantes reunidas en 1582. Traducida esta pasión en términos del amor cortés podrla decirse que no hay esperanza de conseguir el tan ansiado "galardón" e increpa a su deseo:

Conoce tu presumpción, mira que subes el buelo donde falta el galardón (Herrera, 1985, 158)

Hay una superposición del mito de ícaro, que cae cuando ya se hallaba cerca del sol, con el amante que no recibe el "galardón". El descubrimiento de Ícaro se infilttra en el código del amor cortés: la osadla no se ve correspondida con el "galardón". En conexión con su obra de corte petrarquista el poeta se presenta insistiendo en su porfia:

Sigo al fin mi furor, porque mudarme

no es onra ya, ni justo que $s^{\circ}$ estime

${ }^{15}$ Se reilera A. Prieto en señalar la consciente separación que Herrera hizo de su poesía cancioneril y de su poesia petrarquista. Esto explica la no inclusión de las composiciones en metros castellanos dentro de Alganas de 1582. "Quiero decis que Herrera distingue adecuadamente el cauce cancioneril y el petrarquista, y asi como en el primero se entrega a una viva ıradición cortés, en su préctica poética petrarquista no juzgo muy oportuno buscar algo que, como el "amor contés" tenía ya un largo proceso de diseminación e intelectualización desde Cavalcanti. En favor de ello es significativo que en su edición de Algumas no se le ocurriera incomorar ni la más cercana poesla cancioneril" (1987,588). Por mi pante, adelanto que Herrera estableció un vínculo de unión entre ambos cauces, bien es cierto que nunca de forma sistemática. Este vinculo es la inserctón de İcaro en la poesia cancioneril. Sin embargo, las convenciones tanto retóricas como iconológicas de la poesía cortesana permanecieron sólidas y no permitieron una mayor derjuación del sistema iconológico petrarquista hacia la poesia en la línea de El Cancionero general. De ahl, la separación en la que insiste A. Pricto. 
ta mal de quien tan bien rindió su pecho. (Herrera, 1985,356)

escribe en el soneto prologal de 1582, Otro detalle que prueba la inserción de la iconología procedente de la temática petrarquista son los últimos versos de la composición que estoy tratando:

Huirán, qual niebla del viento,

$\mathrm{mis}$ desseos consumidos,

porque no sobre al tormento

sino solos mis gemidos. (Herrera, 1985,160)

La niebla que se deshace por la acción del viento es una imagen de ascendencia petrarquista que aparece dentro del Canzoniere: "Come nebbia al venio" (CXXXIII,v. 3) ${ }^{16}$. Esta imagen fue del gusto de Herrera y al menos la he constatado en otras tres ocasiones, fuera ya del cauce cancioneril ${ }^{17}$. Herrera había asumido la corriente petrarquista y no pudo sustraerse a la tentación de enriquecer, de forma puntual y muy subrepticiamente, la tradición cancioneril con las gemas petrarquistas. Sólo hacia falta saber cómo engastarlas.

Si ya hemos visto el impulso ascensional en la poesía herreriana, no extrañará que en el extremo de ese vuelo se halle la luz, luz que ya en e] Marqués de Santillana - habíamos visto- procedia del rostro de la amada:

Leuantásteme en la cumbre

para derribarme luego;

no pude sufrit la lumbre,

y cai turbado y ciego. (Herrera, 1985,161)

La traducción en términos de una retórica más afin a la usada por la poesía cancioneri] podría ser la que manifiestan estos versos:

Atreuióse el coraçón,

y a ossadia tan injusta

Amor le da en galardón

la muerte por gloria justa. (Herrera, 1985, 162)

Podrían establecerse los sigujentes paralelismos:

\begin{tabular}{|l||}
\hline $\begin{array}{l}\text { Atrevimiento--...-.-> Levantar en la cumbre } \\
\text { osadía }\end{array}$ \\
\hline Galardón--.---...--> caida \\
\hline
\end{tabular}

${ }^{16}$ Para otras referencias a esta imagen dentro del petrarquismo Pilar Manero (1990,645-652).

${ }^{17}$ "cual rota niebla por el viento" (1985,396); "No assi tan presto aparta el viento leve, / $\mathrm{i}$ dissipa las nieblas..." $(1985,441)$ y "cual niebla que la esparze y rompe el viento." (1985,695). 
muerte

Estos parale lismos son los que hacen posible la inserción del mito de Ícaro. E] léxico como atrevímiento, osadía, galardón, muerte no disonaba en el cauce métrico castellano. Lo que resultaba novedoso es la redistribución que lleva a comparar el "galardón" con la muerte, redistribución posibilitada por la actuación subterránea del paradigma de Ícaro: mito que organiza la dicotomía osadia/temor, uno de los pilares de la producción italianizante de Herrera ${ }^{18}$.

Otra clara alusión al mito de Ícaro se desarrolla en los siguientes versos:

Con vn desseo encendido

me leuanto en alto buelo,

y sin temor, atreuido,

las alas pongo en el cielo;

mas no pueden sustentarme

las fuerças de este desseo,

y quando menos lo creo

siento en el mar anegarme. (Herrera, 1985,168)

Ese "deseo encendido" que vuela al cielo para anegarse luego en el mar cual nuevo Ícaro vuelve a aparecer en otra composición dedicada a los ojos de la amada y en el que las alusiones, si es que existen, a Ícaro están sumamente diluidas. No deja por ello de ser significativo que la composición esté dedicada a los ojos de la amada convertidos ahora en dos soles. Dice el poeta:

\section{Adondequiera que os veo \\ todos mis males oluido, y en vuestra luz encendido \\ lleuáis, qual Hado, el desseo. (Herrera, 1985,178)}

Determinados clichés provocan asociaciones hasta entonces inesperadas. El sintagma "desseo encendido" actủa a modo de acicate sobre el lector trayéndole a la memoria otros versos en los que la alusión al temerario hijo de Dédalo eran más claras. La lectura global del corpus poético herreriano produce una modificación interactiva entre las distintas composiciones; todo debido a una voluntad férrea de crearse un universo expresivo propio que atraiga en torno a si las diferentes formulaciones

18 Nicasio Salvador habla de "galardón postrimero" (muerte) en Diego del Castillo, poeta incluido en el Cancionero de Estriniga (1977,283). Creo, en cambio, que es más usual en la poética cuatrocentista la invocación a la muerte para librarse asi del dolor. 
metafóricas creando una armonla entre ellas. Motivos temáticos petrarquistas penetran en las composiciones cancioneriles si bien es cierto que de una forma solapada y no de manera tan sistemática como pudiera desprenderse de la lectura de estas llneas.

Versos como los que siguen:

porque la luz de tus ojos

de tal suerte me abrasó,

que lo mortal apuró

y me hizo sus despojos. (Herrera, 1985, 19I)

muestran bien a las claras su raiz cancioneril. Pero, como si se tratase de un nuevo Jano bifronte, también miran hacia el quehacer poético de la poesla tlpica de Herrera en que se asemeja a los mIsticos: el fuego de la amada apura lo mortal del amante. Hay una superación de la materia a causa de la acción transfiguradora de la luz. Sin embargo, cerca estamos tambjén de los semas que convenientemente dispuestos nos acercarlan a las iconologías de Ícaro y Faetón: luz que destruye al poeta.

Faetón será también otro personaje mitológico que acude a los metros castellanos de la poesla de Herrera con significado semejante al de Ícaro ${ }^{19}$. Tras narrar la fábula del hijo de Apolo escribe Herrera:

yo, que de mi Sol hermoso

presuml la pura Jumbre,

i, atrevido i animoso,

no desmayo en l'alta cumbre. (Herrera, I 985, I 96)

"Cumbre" y "Jumbre" son palabras que ya han aparecido en otro ejemplo en la misma posición (final de verso) posibilitando una asociación

${ }^{19}$ No habla Gallego Morell de Faelón a propósito de la poesía cancioneril porque "Hasta cl Renacimiento no surge lo que pudieramos llamar la mitologia como género literario, sólo la nueva mirada de simpatia a los clásicos que ensayan los humanistas ha podido traer cl rejuventecimiento de temas literarios olvidados a to largo de la Edad Media." (1961,31). Recuerda este critico el significado de osadta amorosa que este mito conlleva e inmedialamente cita los versos en metros castellanos de Herrera $(1961,32)$. El mismo Hertera dedica un largo comentario a Faetón en sus eruditas Anataciones para concluir: "Pero algunos significan esta fibula moralmente conten los que presumiendo subir con temeraria osadla más alto que lo que pueden sus fuerzas, al fin caen en tierma." (Gallego Morell,1972,348). Tras esto trac a colación el docto comentarista de Garcilaso sus propios versos cancioneriles en los que trata a Faetón, prueba esto de que tería presente no sólo su producción petrarquista. Turner (1977,80, nota 31) señala un cjemplo en que lohan de Andujjar, poeta cuatrocentista, se vale de Factón como término de comparación con la empresa osada del poeta al intentar describir la belleza de una condesa. La simonimia semántica entre Icaro y Fuetón queda probada por la contaminación del primero con elementos del segundo, tales como el incendio de las alas de ícaro (Tumer, 1977,104). El primero en tratar a Faetón e Ícaro como tritos de significado parecido fue Dante (Tumer, 1977.24) 
de ideas que remite a las fábulas tanto de Ícaro como de Faetón. Samuel Levin habla de apareamiento poético para ciertas palabras que contraen un tipo de relación textual muy determinada:

Sólo cuando se dan esas equivalencias entre palabras y cuando las palabras asi equivalentes ocupan posiciones tambien equivalentes en el sintagma, es cuando podemos decir que nos encontramos ante un apareamiento poético, emparejamiento que viene a fundir la forma y el contenido del poema $(1990,64)$

Observamos cómo la "subgramática" propia del lenguaje poético herreriano articulado en este caso sobre el mito de Faetón o Ícaro hace equivalentes en el paradigma a "lumbre" y "cumbre" a la que se une su posición, también equivalente, en la distribución sintagmática propiciada por la rima. Estos versos vienen a apoyar la tesis que sostengo:

Traspórtome desde el suelo

mas quando miro la lumbre, antes de tocar la cumbre

las alas faltan al buelo. (Herrera,1985,206)

"Lumbre" y "cumbre" entablan relaciones idénticas a las indicadas en el ejemplo anterior lo que nos lleva a pensar que Herrera usa de forma semejante ambas figuras mitológicas ${ }^{20}$.

Lo que pretendo sugerir es que hay todo un sistema poético que se está creando y que transmina toda composición lírica. En los poemas de corte italianizante el mito de ícaro está omnipresente. Esta actitud obsesiva fue notada por J. Tumer (1977,75-76) que escribe:

Icarus seems to have held a particular fascination for Fernando de Herrera. (...) The theme of daring (osadia, atrevimiento) is ubiquitous in Herrera's poetry and is often associated with the

${ }^{20}$ En las composiciones fuera de la órbita cancioneril tambien las palabras "cumbre" y "lumbre" contraen relaciones semánticas propiciadas por la asociación fónica que establece la rima: "i sé bien qu' alcançara con su lumbre / gloria'l dolor i grave mal que siento, / i a mi nombre lugar en alta cumbre." (Herrera, 1985.594). "Él mira de la sacra, ecelsa cumbre / los qu'erramos, i el gozo i vano intento / desprecia con aguda i pura lumbre." (Herrera, 1985,624). "Yo que cuidé estrenar ta pura lumbre, / y de mi Sol regir los cercos d'oro, / dichoso Automedón, con diestra suerte, / cal, abierto el pecho, de la cumbre,"(Herrera, 1985,646). Otros cjemplos se pueden encontrar en las páginas $451,534,587$. La cursiva es mia. No paso por alto Pla restricción de la rima en -umbre que conforma un paradigma necesariamente reducido. Ambos términos se hallaban en la lista de rimas acabadas en -umbre que proporciona Juan Diaz Rengifo en su Arte poérica española de $1606(1977,243)$. Lo que quiero hacer notar es la frecuencia con que Herrera relaciona ambas palabras por medio de la rima. 
peril of the fatal charms of a lady whose literary name is Luz o Lumbre.

Sin embargo, no ha de pensarse en Ícaro, a mi entender, como el nucleo generador de la producción poética de Herrera. Abundantes son los poemas en metro italiano en donde se trata la fábula del temerario joven, pero no es desden̉able en manera alguna el número de composiciones en donde Herrera usa un lenguaje que recuerda a los moldes expresivos del misticismo ${ }^{21}$. En cuanto el "pensamiento atrevido" se trasmute en el alma que desea liberarse de su yugo terrenal en busqueda de una Luz, trocada ahora en "ardor santo", nos hallaremos ante registros que recuerdan a la poesía ascético-mística:

Mi alma no soporta pesar tanto,

i, el nudo que la estrecha desatado,

ligera jrá con buelo acelerado,

sin descansar siguiendo su ardor santo. (Herrera, 1985,554)

Todo el sistema poético de la poesía amatoria de Herrera pasa por la identificación de su amada con la "Luz" o cualquier otro elemento lumínico. Esta creación de Luz como senhal para su amada rige un haz de constelaciones metafóricas de muy diversa procedencia que son asimiladas y adaptadas a un lenguaje propio. En ocasiones nos encontraremos a Ícaro; en otras, al alma que va en vuelo a buscar una amada quintaesenciada e identificada con la belleza. Ambos comparten un impulso ascencional. Este sistema iconológico es e] que empuja sobre la poesía de corte cancioneril. Aprovechando elementos como la muerte, fuego, osadía, luz que aparecían dispersos por los cancioneros castellanos y tras haber aprendido de la tradición petrarquista la plasticidad que brindaba el uso de la mitología, Herrera proyecta la iconología de Ícaro en metros castellanos ${ }^{22}$. Todavía se

${ }^{21}$ Esto ha llevado en algun caso a hacer afimaciones como las siguientes:"El carácter místico es el que en đefinitiva triunfa en su pasión arnorosa, (Montori de Gutiértez, 1977,74). Esta misma autora se expresa en los siguientes términos que recuerdan también el misticismo del sevillano "La poesia amorosa de Herrera es, pues, una constante expresión de heroísmo erótico, una búsqueda de la Belleza, a la que el alma quiere llegar a través de la exaltación de la hermosura de la Amada." (1977,76). Macri habla de "heroismo erótico" $(1972,493)$ que encarna el amante que persigue la esencia del fuego y de la luz en una suerte de purifieación final. "Es, en fin, el carnino para penetrar en la inaccesible región de la Betleza, la cual invade los sentidos y fluye por las veris como dulce fusego en el que se transfigura el alma." (Macri, 1972,495).

${ }^{22}$ Alusiones al mito de f́caro en métrica de tipo cancioneril pueden verse en Diego Hurtado de Mendoza (Tumer, 1977,66-67) quien se mostró más innovador que Herrera al incorporar nuevos registros a la poesia heredera de los cancioneros cuatrocentistas (A. Ptieto, 1984, 102). Referencias a la caida del poeta desde lo aito se observan en algutnos versos de P. Lainez: "Vos sabejs al que perdió / el bien que, sin culpa yo, / cual la tendrá agora el mal, / vos sabeis si está mortal / quien 
estaba fraguando la senhal Luz para la condesa de Gelves pero ello no obstaba para que se iniciaran los primeros tanteos. Hay que tener en cuenta que mientras Herrera componía poemas en quintillas también escribja sonetos y otras poesias en metros de tradición italiana. De 1578 es el soneto que trata el motivo de la simple mariposa que se va a consumir en la llama:

La incauta y descuydada mariposa, de la belleza de la luz rendida, en torno della buela y, ençendida, pierde en ella la vida, presurosa. (Нетrera, 1985,278)

Estrecha relación es la que guarda este motivo de la mariposa con Ícaro tal y como señala Tumer (1977,91 y passim). Ambos se consumen en el fuego. En tomo a la concepción de la amada como sol se origina una variopinta lista de motivos poéticos que contraen entre sl relaciones de proximidad ${ }^{23}$. Al motivo de la mariposa y al de Ícaro/Faetón se agrega frecuentemente el del Ave Fénix (Turner, 1977,52,63 y passim).

También de 1578 es la elegla que comienza "Ardo en el resplandor y en la pureza" (Herrera,1985,289-291). En esta composición puede observarse una cierta ósmosis entre los moldes cancioneriles y los petrarquistas. El poeta parece deleitarse en su pena:

Nunca me satisfago de mi pena,

que siempre miro en ella, y all tengo

el fin de todo el bien que Amor ordena. (Herrea, 1985,290)

El deseo que guía ahora al poeta es "alto" y "amoroso" de tal manera que habremos de pensar de nuevo en lcaro cuando leemos:

Con la belleza agena a formar vengo

la suya soberana, y me leuanto

con ella adonde apena me sostengo. (Herrera, 1985,290)

de tan alto cayó" (1950,84). Otro cjemplo "Yo me vi dichoso, cuando / la muerte estaba esperando; / y cstando en alegre vida / de tan alto di tan grat caida / que me estoy ya confesando." $(1950,86)$. Ya en el molde métrico del soneto escribe Lainez "Con tan sublime vuelo he levantado I la mente a la amorasa fantasia, / vega abundante y fértil, desde el día / que vuestra clara lumbre me ha guiado". Recuerdan estos versos a la formulación que encontraremos de lcaro en la Galatea de Cervantes. El pensamiento que se encumbra en vuelo aparece también en los versos de Soria: "Mi cautivo pensamiento / tan alto subio a bolar, / que el más ciego entendimiento / vera su atrevimiento, /si razon ay en amar:" (Foulche-Delbosc, 1915,11, 258 b)

${ }^{23}$ "The image of the butterny, atracted to the very flame that must kill it, appears also as an expression of the lover's situation. Here the tradition of the butterly as a metaphor of the frailty of human life -for the Greeks the butterlly was a symbol for the human soul- joins the developing tradition of Icarus as the ill-fated lover. Both Phaethon and the butterfly will be associated with lcarus frequently in Spanish poems." (Tumer, 1977,55) Gregorio Cabello ha tratado tembien el motivo de la mariposa que se consume en la llama (1995,65-108) 
Este Ícaro es un perseguidor de la belleza que se inflarna en la Luz como alma arrebatada. El gozo y ventura que ahora experimenta el poeta distan mucho del sufrimiento que atenazaba hasta los tuétanos al poeta en sus composiciones cancioneriles. La osadía como tal no existe en estos versos $y$, por tanto, no hay actos punibles ni vestigio alguno de la pasión amorosa como un error que se ha de pagar:

Dichoso yo, que tuue tal ventura, que la perfecta luz busqué ençendido, no engañado en fingida compostura. (Herrera, 1985,291).

Con estos ejemplos he querido dar a ver una muestra de la maleabilidad del acervo poético en la manos de Herrera. Frente a un Ícaro que se insertaba en el cauce cancioneril como prototipo de la osadia (apreciable también en la obra italianizante) observamos en otros versos una configuración del mito rayana los moldes expresivos de la mistica, una mistica muy particular que persigue la unión con el dios de la belleza.

Es en definitiva ese impulso ascensional lo que permite la integración de los mitos de Ícaro y Faetón con una retórica de esencia mística. En la poesia cancioneril existía una amada que era el culmen de la belleza y que, además, gozaba de una posición social elevada, lo que se tradujo en versos de Manrique en la imagen poética de la escala de amor. Esta escala se convirtió en vuelo osado con el que el pensamiento del poeta pretendia al idolo bello y cruel de una amada inalcanzable. Por galardón, la muerte; $y$ por gloria, la fama de quien tanto amó muriendo.

Por estos años de 1578 tanto la red iconológica que ligaba a Ícaro con el motivo de la mariposa, como el nombre de Luz como senhal de la amada estaban presentes en composiciones italianizantes. Sin embargo, en la poesía de corte cancioneril el mito de ícaro se halla aislado y el nombre de Luz -con mayúscula- no existe. Tanto la retórica como el mundo afectivo que hendia sus raices en los cancioneros castellanos bien pudieran haber actuado a modo de filtro. Algunos de sus elementos constitutivos, convenientemente reelaborados, permitieron que ĺcaro fuese el diluido brocado en el tejido cancioneril. Mas no por ello ha de pensarse que Herrera ignorase la tensión ocasionada por la acción de fuerzas contrarias -osadia y temor- que inundaban los versos castellanos del $\mathrm{XV}^{24}$. Ambas eran placas tectónicas y el deslizarse de una de ellas (en concreto, la osadia) suponia el terremoto icariano que habrla de agitar los cimientos de la tradición poética castellana.

${ }^{24}$ Herrera también pedirá la muerie como único remedio: "Tal estoi, que ya no espero / remedio a mi mal esquivo; / ni viuo ya porque viuo; / y muero porque no muero." (Herrera, 1985, 189) 
Asjstimos a la ramificación del sistema metafórico herreriano que se infiltra y gotea hermosas esencias en la poesía cancioneril. Me inclino por esta interpretación a pensar que unas escasas alusiones al mito de ĺcaro pudieran haber servido de vasamento a un ulterior sistema metafórico capaz de sustentar toda su lírica amorosa. Supondrla esto ignorar el hecho de alternancia y simultaneidad de escritura de poemas cancioneriles y otras de corte italianizante en los años precedentes a 1582. Además, cada corriente poética posela una personalidad propia si bien es cierto que los meandros y laberinticos vericuetos poéticos del XV1 propiciaron un ayuntamiento de las diversas poéticas (Blecua,1970,11-24; Lapesa,1985,213-238; A. Prieto, 1984,37-58). A esta confluencia de torrentes pertenece lo que aqul denomino inserción del mito de ícaro en la poesía cancioneril. Herrera no fue ajeno a sincretismos y asi lo expone Montori de Gutiérrez: "La lucha entre amor platónico, unida al atavismo medieval de la contraposición entre inteligencia y sentidos, se trasluce también de manera decisiva en sus versos" $(1977,74)^{25}$. Es Herrera en este sentido creador de puentes, alivio de caminantes que pretenden conquistar ambas riberas.

\section{EL CONTRAPUNTO CERVANTINO.}

Tres años después de publicar Herrera su antología de versos ve la luz la "novela" pastoril La Galatea: primogénito de los vástagos literarios de Cervantes. Este libro de pastores comienza con un poema puesto en boca de Elicio, uno de los enamorados de la protagonista femenina que da tltulo al libro. Elicio encauza su pena en cuatro octavas reales que se hallan imbuidas de la técnica manierista que distribúa el contenido poético en pluralidades. Sin embargo, no es éste el poema sobre el que quiero fijar mi atención. El siguiente poema que nos encontramos, pocas páginas más adelante, pertenece también a Elicio. Frente al anteriot no está compuesto en octavas reales, estrofa de procedencia italiana, sino en coplas de arte mayor octosilábicas muy usadas en los cancioneros del XV. También se distancia del poema anterior en el contenido. Si el poema en octavas reales trataba de Jas relaciones entre poeta y naturaleza y de la casulstica metafórica del amor, el poema en octosilabos del que me ocuparé es una interpelación que Elicio hace a su propio pensamiento. Con ello se establece una oposición entre los dos primeros poemas: el personaje es el mismo (Elicio) pero tanto su

${ }^{25}$ "Herrera refuerza posiciones extremas y confluyentes en una sintesis superior: el simbolismo sicológico cancioneril y la mística y pánica embriaguez del neoplatonismo renacentista." (Macri,1972,489). En otro lugar habla este critico de la combinación del sicologismo del $\mathrm{XV}$ castellano y del "platonismo antropológico" del Renacimiento. (Macri, 1972,478). 
contenido como su métrica difieren de una manera notable. Con ello se evita la monotonia que conllevaria oir al mismo pastor quejarse en "métrico llanto" dos veces seguidas y de la misma manera.

Hertera habia aprovechado el pensamiento osado o el encendido deseo para remontar su "buelo" en temerario intento. Solicitar a una amada de marmóreo pecho estaba destinado al fracaso y, por consiguiente, la caída desde la cumbre. Este pensamiento en su alzarse sembrará también vagas alusiones a İcaro en el poema cervantino ${ }^{26}$. Tenemos, pues, algunos nexos entre Herrera y Cervantes: el uso de una estrofa de cuño cancioneril y la interpelación a su propio pensamiento que se eleva hacia la amada. Conviene, sin embargo, antes que nada analizar el contexto narrativo en el que se integra el poema perteneciente a La Galatea.

La prosa que antecede al poema relata el amor que Elicio profesaba a Galatea. Éste alberga ciertas ilusiones de ver su amor correspondido: "Imaginábase Elicio que, pues Galatea no desdeñaba sus servicios, que tendrian buen suceso sus deseos. "Ciertamente el uso del término "servicios" en un contexto amoroso nos hace pensar inmediatamente en algún vestigio de la práctica del amor cortés ${ }^{27}$. Si bien esto pudiera ser cierto haciendo una serie no pequeña de salvedades, habría que precisar que afectaría sólo al uso lírico-figurado del término. No puede soslayarse el otro significado que propiciaría su sentido referencial narrativo. Elicio es un pastor enamorado $y$ como tal puede hacer una serie de favores (o servicios) a la pastora objeto de sus pensarnientos: por ejemplo, cuidar de su ganado. Debido a esta doble perspectiva que contempla tanto el sentido lírico como el narrativo el término se ve arrastrado a una ambiguedad semántica. Por otro lado, se

${ }^{26}$ La fantasla y no el pensamiento se encumbrará en los osados pastorts que pretenden a una amada que no merecen: "porque si todos sus laggrimas y sospiros se causaron de ver que no se responde a su voluntad como se debe y con la paga que se requiere, habria de considerar primero adónde levantaron la fantasia; y si la subicron más arriba de lo que su merecimiento alcanza, no es maravilla que, cual nuevos learos, caigan abrasados en el rio de las miserias, de las cuales no tendrá culpa amor, sino su Jocura." (Cervantes, 1995,445). Sobre el concepto de fantasia se ocupa G Serés (1994, 207-236). Cervantes trata el milo de lcaro en otro soneto incluido en la comedia titulada La entretenida: "vuela mi estrecha y débil esperanza" (Cervantes, 1987,55I). Este soneto se halla rodeado de un contexto burlesco que desmitifica la figura del amante/Icaro.

${ }^{27}$ Otis $\mathrm{H}$. Green observa la mezcla de rasgos de una concepción platónica del amor con una visión propia del "fin 'amors" (1969,I,222-23।), John T, Cull (1986,63-80) examina dentro de la casulstica amorosa el juego cervantino con la expectativas del lector. Consigue con ello crear tha ambiguedad léxica relacionada con una concepción del amor que se debate entre dos extremos: el amor considerado como furor pasional y el amor de raigambre platónica. La solución a esta paradoja está constiuida por dos remedios; el malrimonio y la razón (A. Parker, 1986,139). 
observa que Elicio no es capaz de declararse. La honestidad de Galatea es el freno que anuda su lengua:

al enamorado pastor se le helaban las palabras en la boca, y quedábase solamente con el gusto de aquel primer movimiento, por parecerle que a la honestidad de Galatea se le hacia agravio en tratarle de cosas que en alguna manera pudiesen tener sombra de no ser tan honestas que la misma honestidad en ella[s] se transformase. (Cervantes, 1995,168)

El careo de la pasión amorosa con la honestidad de la dama provoca la creación de un conflicto interior que se ve plasmado en palabras que, según Avalle-Arce, recuerdan los conocidos versos del comendador Escrivá invocando a la muerte para poner fin a su dolor: "Con estos altibajos de su vida, la pasaba el pastor tan mala que a veces tuviera por bien el mal de perderla, a trueco de no sentir el que causaba no acabarla." (Cervantes, 1995, 168-9) ${ }^{28}$.

De esta manera, el fragmento en el que el narrador nos cuenta la naturaleza del amor de Elicio propicia el arrebato lírico de Elicio cuyo destinatario será su propio pensamiento. Sin embargo, la actitud que adopta el personaje cervantino es muy otra a la que mostraba Herrera. El pensamjento del sevillano que levantaba su "flaco buelo" segula en pos de su furor y acababa pagando su osadia. Elicio opta por aconsejar a su propio pensamiento una suerte de "aurea mediocritas" con el fin de que evite los extremos ${ }^{29}$ :

${ }^{28}$ Escribe Avalle-Arce a propósito de estas lineas de La Galatea:"En esta conceptuosa expresión creo hallar un eco de los famosisimos versos del comendador Escrivá, repelidamente citados y glosados a lo largo del siglo XV1 y comienzos del XVII," (Cervantes, 1987,67). Electivamente, los versos del comendador Escrivá fueron adaptados por Sta Teresa y tomados por Cervantes y más tarde glosados por Lope de Vega en sus Rimas sacras como indica a propósito de unos versos de Manrique de similar temática Vicente Beltrán (Manrique, 1988,78). El comendador Escrivá participa de un tópico que se desarolla frecuentemente en la poesia cancioneril que es la invocación a la muerte para asl acabar con el dolor que le aqueja. Escribe Nicasio Salvador: "La configuración del hombre como mártir de arnor lleva aunado el deseo de la muerte, que deviene en asunto harto frecuente en la lírica cuatrocentista y en otros géneros coetáncos, como la novela sentimental, al tiempo que explica, junto a otras razones, el cono quejumbroso de esta poesía y la repetición temática de Ja queja de amor." (1977,291-292). A mi entender, el influjo no es tanto del comendador Escrivá como del mundo afectivo de ta poesia cancioneril; la relórica y la métrica usada por Cervantes en este poema asi lo señalan.

${ }^{29}$ Este perseguir el justo medio en Cervantes habria que ponerlo, a mi juicio, en relación con las Melamorfosis de Ovidio. Dedalo aeonseja a su hijo que no vuele demasiado bajo ni demasiado allo: de otra manera, el mar o el sol labrarian su desgracia: "instruit et natum imedio" que "ut curras, / /care", ait "moneo, ne, si demissior fbis, / unda gravet pennas, si celsior, ignis adurat: / 
la soberbia:
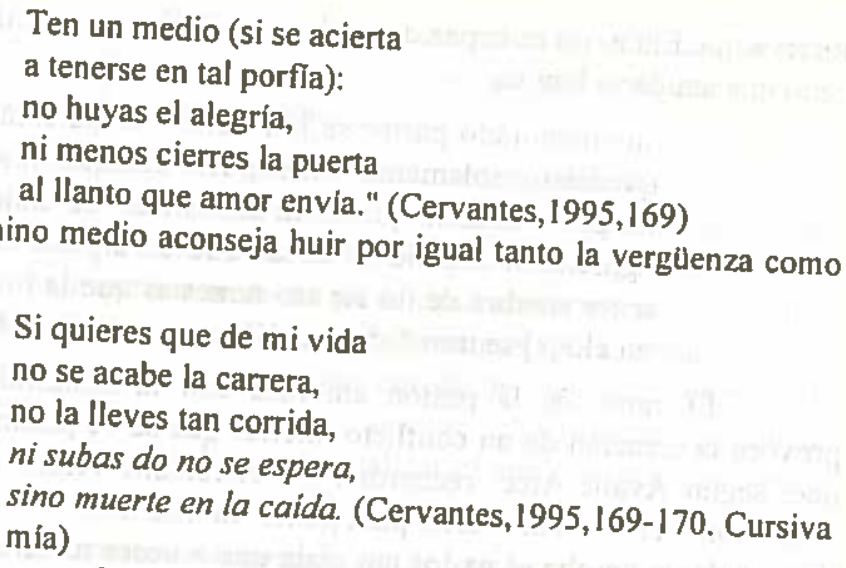

Es al hacer referencia a uno de los extremos que hay que huir (la soberbia y la osadia) cuando encontraremos expresiones que conforman una serie de alusiones al mito de Ícaro:

Ese vuelo peligroso

con que te subes al cielo, (Cervantes, 1995,170)

amada:

Aquello que hace al pensamiento encumbrarse es la belleza de la

\section{Subes tras una beldad}

inter utrumque vola. " (VIII,203-206).Esta relación ha sido puesta de manifiesto por Fucilla (1963, 65), quien además relaciona este poema con otra composición de Diego Hurtado de Mendoza su pasión amor, 1977,66-67). Contrasta tal actitud con la presentada por Herrera que se muesira ufano de pido, señora, el tomento" " (Hem contento / me hallo con mi passión, / que en lugar del galardón / que sentire solamente / no auer muero , 144), "Yo morive tan vfano, / si tu merced lo consiente, / mis males" (Herrerg, 1985,206). Este semprano." (Herrera, 1985,189) o "V fano muero en italianizantes "En los luzientes nudos entaztimiento también aparecerá en composiciones dulce ardia i puro aliento. / cua enalazado, / ufano, yo sufria mi tormento, i co la llama esperança ufana alcava ol buelo" ave arabia, en ella renovado." (Hertera, 1985,612); "tal mi (Herrera, 1985, 657) y entre otros ejemera, 1985,638); "Tan ufano estoi siempre'n la tristeza" cuidado / ufano i sin temor, más mi cjemplos para finalizar "Vivi, cuando Amor quiso, en mi actitudes que tiende un puente entre Cervantes pretende el justo medio, Herrera formas poeticas bien diferenciadas por Herrera. Si extremos lexos del medio" (Herrern manera, están relacionados con f́caro 1985,198 .) Estos extremos, como no podía ser de otra fuego quema / quando no vale el reme en tste caso sufre contaminación con Faetón: "las alas el medio," (Herrera, 1985,157). Este tipo de con / porque con mi muterte tema / extremos lexos del Factón abrasado por el rayo de Jupiter- contaminación -Icaro que quema sus alas al modo de prueba, en mi opinión. las coner - también se dan en la poesla posterior de Herrera, lo que "O, cómo bueta en alto mi desco / sin que su de ambas formas pośticas -italiana y cancioneril-: alas quema / donde ningún remedio sin que su osadla el mal fin temal; / que ya las puntas de sus 30 
que no puede ser mayor; (Cervantes, 1995,171)

Una vez más, el impulso ascensional viene determinado por el hecho de contemplar "un sujeto levantado".

Curiosamente, puede verse en este poema cervantino el uso de una imagen de cuño petrarquista que ya había usado Herrea en un poema de corte cancioneril trenzado de alusiones al mito de licaro. La imagen a la que me refiero es la niebla que se deshace por efecto del viento:

Cuanto más que el amor nace

junto con la confianza,

y en ella [se] ceba y pace;

$y$, en faltando la esperanza,

como niebla se deshace. (Cervantes, 1995,171$)^{30}$

El molde cancioneril parece visible en el poema cervantino. Si ni siquiera el texto en prosa que lo precede ni la métrica fuesen pruebas convincentes, no harja falta sino echar un vistazo a los dos versos que rematan el poema de Elicio:

el morir es vida honrosa;

la pena, gloria extremada. (Cervantes, 1995,171)

Si en Herrera la palabra con la que habla definido el artifico para el uso de Ícaro en los versos cancioneriles era la de inserción, en Cervantes habria que explicarlo en función del cúmulo de relaciones que establecen entre sí la prosa y el verso. En este caso el contexto narrativo proporciona una mejor comprensión del poema de Elicio. No es imprescindible, a diferencia de otros poemas de La Galatea en donde la trama argumental se introduce en los poemas, pero lo dota de una mejor penetración psicológica. Cada verso viene motivado por la situación vital en la que se ve inmerso cada personaje. Es en esta dialéctica prosa/verso y personaje/poema donde, a mi juicio, cobra pleno sentido la poesía de Cervantes. Ignorar el mundo narrativo en Cervantes supone amputar su lf́rica. Definitivamente, en la novela pastoril poesia y prosa se dan la mano no para que el bisturl más o menos agudo del estudioso se empeñe en separarlas y analizarlas por separado.

A modo de recapitulación podría afirmarse que Herrera se valió de elementos que venían acuñados por la tradición poética enraizada en los cancioneros del XV. El poeta, enamorado osado, que rompla el silencio

${ }^{30}$ La esperanza es un elemento caracterizador de los personajes de La Galatea según ha señalado Barbara Mujica (1986,171-209). No aparece en estos versos de Cervantes el otro elemento que va haciendo parcja con la niebla que es el viento que al soplar la deshace. 
impuesto se abrasaba en la belleza de la amada cuyas excelencias la habian llevado en ocasiones a ser comparada con la luz. Otro fuego, éste interior, atenazaba la médula del abrumado amante. En la sentina del dolor se entreve una salida al conflicto planteado entre razón y pasión: la invocación a la muerte, capaz, esta vez sí, de arrebatar e] "dolorido sentir". A esta tradición Herrera aunó la experiencia del petrarquismo de tal manera que, tras una conveniente reordenación de ciertos motivos, proyectó la figura de ĺcaro que pasará a ser parangón mítico del enamorado cortés. De este modo se puede explicar que el galardón conseguido sea, pongo por caso, la muerte ${ }^{3 \prime}$.

El mito de İcaro aparece también con asiduidad en el resto de la poesla herreriana y forma parte esencial de su sistema expresivo. Por ello hablo de una inserción como resultante de un empuje de la cosmovisión poética propia sobre la poética cancioneril, mundo poético heredado.

Por contra, el uso de alusiones a ĺcaro en la composición cervantina estudiada encierra una actitud diferente a la de Herrera. Frente al seguimiento del furor de éste, aquél aboga por un término medio, huyendo asl de los extremos. Es al hablar de uno de esos extremos cuando se encuentran las citadas alusiones, siempre más diluidas que en Herrera, a Ícaro. No me parece apropiado el término de inserción en Cervantes pues éste no había fabricado un mundo poético propio como Herrera que pudieșe articular de manera diferente el léxico cancioneril. La motivación textual en Cervantes viene dada por la dialéctica existente entre la poesla y la prosa. La situación vital en Elicio propicia el poema. Que en Elicio haya un conflicto interior explica la adopción del sistema cancioneril en e] cual pueden verse vagas alusiones a lcaro. Finalmente, pudiera afirmarse que el uso de una misma imagen, caso de la "niebla" que se deshace, puede ser

"Los poetas cancioneriles habian intentado una revitalización de la metáforn de la muerte por amor:"A diferencia de la metáfora feudal, no se puede sostener que en el caso de la muerte de amor haya habido una" Jexicalización plena; sin embargo, cuando un tópico es utilizado tan profusamente duranic decenios, pierde expresividad aun sin haberse lexicalizado. De esta manera, como sucedia con el senvicio de amor, si el pocta debe utilizar la muerte de amor como metálora, debe revitalizar de algún modo un lugar común que, de otra forma, pasaria inadvertido." (Casas Rigall,1995,71). Los procedimientos de revitalización, segin este estudioso, de la metúfora de la "muerte de amor" son tres: situar la metáfora en un contexto en el que haya elementos incluidos en el campo semántico de la muerte; yuxtaponer "la muerte de amor" en relación opositiva a conceptos que hagan referencia al campo semántico de la vida y la creación de paradojas que relacionen $y_{1}$ a la vez, deslinden la muerte física de la muerte de amor. La inserción del mito de ícaro en la poesia de conte cancioneril actuaria, a mi modo de ver, como un recurso que, incorporado de la poética petrarquista, ayudaria a deslexicalizar la manida "muerie de amor" añadiendo una dimensión mitica al amante desesperado. 
fruto de una casualidad aunque probado es el gusto de Cervantes por la poesía de Herrera ${ }^{32}$.

Por todo ello prefiero hablar de inserción del mito de ícaro en la poesia cancioneril en el caso de Herrera y de dialéctica lírico-narrativa en el caso de Cervantes. El contraste de actitudes y procedimientos es obvio a mi entender.

Frente al gozoso empeño de Herrera por arder cual mariposa en "piramidal llama", Cervantes contempla, por boca de Elicio, la conveniencia de un término medio en un mundo de pasiones contrarias.

Transcurtirá el tiempo y poetas como Góngora no podrlan sustraerse al influjo de İcaro ni siquiera en la cumbre de su poesía: hablo, claro está, de Las Soledades (Micó,1990,68-82). Otro gran amigo y admirador de Góngora, el Conde de Vi]lamediana, insuflará vital aliento al mito de alada osadía en lo que Juan Manuel Rozas ha denominado "cancionero blanco" ${ }^{\text {"33 }}$. Prueba esto la vigencia de un atrevido pensamiento que cada cual supo interpretar, alquímica locura, a su modo.

\section{BIBIOGRAFIA}

Blecua, José Manuel. 1970. "Corrientes poéticas en el siglo XVI" Sobre poesía de la Edad de Oro. Madrid: Gredos (Campo abierto Vll). pp.1 1-24. Publicado anteriormente en Insula,80,(1952)

Bruyne, Edgar de. 1987. La estélica de la Edad Media. Madrid: Visor.

Cabello Gregorio. 1995. "La mariposa en cenizas desatada: una imagen petrarquista en la linea aúrea, o el drama espiritual que combate dentro de si" en Estudjos sobre tradición clásica y petrarquismo en el Siglo de Oro. Almerfa: Universidad de Almerla. Publicado anteriormente en Estudios humanisticosFilologia 12 y 13, 1990 y 199, pp. 255-277 y 57-75 respectivamente.

${ }^{32}$ Cervantes dedicó un sonelo a la muerte de Herrera. Véase las páginas que le dedica a este poema Adrienne Laskier Martín (1985,213-220). No deja de ser significativo que Cervantes acuda a la rima "cumbre/lumbre" en su soneto, rasgo de la poética hereriana sobre el que he llamado la atención. No podia faltar en el "Canto de Calfope" la referencia a Hertera (Cervantes, 1995,573. 574). De igual manera rindió homenaje al divino sevillano en su particular Vlaje del Parnaso (cap. 11, vv. 61-72)

33" EI tema icariano rezuma la mayor parte de esta poesia, con los motivos de la luz, de la gloria, de la altura, de la mirada que hipnotiza por su resplandor, como el sol hipnotizó a ĺcaro, o la lámpara a la mariposa (...). En esto es el seguidor mís destacado de Herrera, al que supera, dentro del tema central, en el abuso de las nociones de peligro y quietismo, dando un paso más hacia la versión bartoca del petrarquismo. " $(1980,23)$ 
Capellanus, Andreas. 1985. De Amore. Tratado sobre el amor. Trad. Inés Creixell Vidal-Quadras. Barcelona: El Festín de Esopo, Quaderns Crema.

Casas Rigall, Juan. 1995. Agudeza y retórica en la poesia amorosa de cancionero. Santiago: Universidade de Santiago de Compostela.

Cervantes, Miguel de. 1991. Viage del Parnaso. Poesias varias. ed. Elias L. Rivers. Madrid: Espasa-Calpe. Clásicos Castellanos. $n^{\circ} 23$.

Cervantes, Miguel de. 1995. La Galatea. eds. Francisco López Estrada y Marja Teresa López Garcia-Berdoy. Madrid, Cátedra.

Cervantes, Miguel de. 1987. Teatro completo. eds. Florencio Sevilla Arroyo y Antonio Rey Hazas. Barcelona: Planeta.

Cervantes, Miguel de. 1987a. La Galatea. ed. Juan Bautista Avalle-Arce. Madrid: Clásicos Castellanos.

Cull, John T. 1986. "Another Look of Love in La Galatea" Cervantes and the Pastoral. Cleveland: Penn State University-Behrend CollegeCleveland State University. pp. 63-80.

Diaz Rengifo, Juan. 1977. Arte poética española. Madrid: Servicio de Publicaciones del Ministerio de Educación y Ciencia. Colección Primeras Ediciones, $n^{\circ}$ 7. (facsímil de la primera edición de 1606)

Egido, Aurora. 1990. "La poética del silencio en el Siglo de Oro. Su pervivencia". Fronteras de la poesia en el Barroco. Barcelona: Critica. pp.56-84. Publicado anteriormente en Bulletin Hispanique, LXXXVIII,1-2 (1986), pp. 63-120

Foulché-Delbosc. ed. 1915. Cancionero castellano del siglo XV, Il. Madrid: Nueva Biblioteca de Autores Españoles.

Fucilla, Joseph G. 1963. "Etapas en el desarrollo del mito de Icaro en el Renacimiento y en el Siglo de Oro" Superbi colli e althe saggi. Roma: Caruci Edotora. Pp. 45-84.

Gallego Morell, Antonio. 1961. El mito de Faetón en la literatura española. Madrid: C.S.I.C.

Gallego Morell, Antonio.(ed.) 1972. Garcilaso de la Vega y sus comentaristas, Madrid: Gredos.

Green, Otis H. 1969. España y la tradición occidental, 1. Madrid: Gredos.

Hebreo, León. 1986. Diálogos de amor. Trad. Carlos Mazo. Ed. José María Reyes. Barcelona: P.P.U. 
Hertera, Fernando de. 1985. Poesía castellana original completa. ed. Critóbal Cuevas: Madrid, Cátedra.

Lainez, Pedro. 1950. Poesias de Pedro Lainez. ed. Antonio Marin Ocete. Granda: Universidad de Granada.

Lapesa, Rafael. 1985. "Poesía de cancionero y poesía italianizante" Garcilaso: estudios completos. Madrid: Istmo. pp. 213-238. Publicado anteriormente en De la Edad Media a muestros dias. Estudios de historia literaria. Madrid: Gredos. 1967. pp. 145-171.

Laskier Martin, Adrienne. 1985. "El soneto a la muerte de Herrera: texto y contexto". Anales cervantinos XXIIl.pp. 213-220.

Le Gentil, Pierre. 1981. La poésie lyrique espagnole et portugaise à la fin du moyen age. Genève, Paris: Slatkine. 2 vol.

Levin, Samuel. 1990. Estrucuturas lingüisticas en la poesia. Madrid: Cátedra. $5^{\lrcorner}$edición.

Lewis, C. S. 1988. The Allegory of Love. Oxford: Oxford University Press. reimpresión de 1977.

Lida, M Rosa. 1984a. "La Dama como obra maestra de Dios". Estudios sobre la literatura del Siglo XV. Madrid: Porrúa-Turanzas. pp. 179 290.

Lida, $M^{3}$ Rosa. 1984b. Juan de Mena, poeta del prerrenacimiento español. México: El Colegio de México. $2^{2}$ ed. (1"a ed. 1950)

Macri, Oreste. 1972. Fernando de Herrera. Madrid: Gredos.

Manero Sorolla, $\mathrm{M}^{\mathrm{a}}$ Pilar. 1990. Imágenes petrarquistas en la lírica española del Renacimiento. Barcelona: P.P.U.

Manero Sorolla, Ma Pilar. 1991. "La imagen del A ve Fénix en la poesia de cancionero. Notas para un estudio". Anuario de Estudios Medievales, XXI, Barcelona: 1991.pp.291-305

Manrique, Jorge. 1988. Poesia completa. ed. Vicente Beltrán. Barcelona: Planeta.

Markale, Jean. 1987. L amour courtois ou le couple infernal. Paris: Éditions Imago.

Mena, Juan de. 1989. Obras completas. ed. Miguel Ángel Pérez Priego. Barcelona. Planeta.

Mícó, José María. 1990. La fragua de las Soledades. Barcelona. Sirmio. 
Montori de Gutiérrez, Violeta. 1977. Ideas estéticas y poesia de Fernando de Herrera. Miami. Ediciones Universal.

Mújica, Barbara. 1986. Iberian Pastoral Characters. Washington: Scripta Humanistica.

Ovidio. 1977. Metamorphoses, Cambridge, Massachusetts: Loeb Clasical Library. Harvard University Press. 2 vol.

Parker, Alexander. 1986, La flosofía del amor en la literalura española 1480-1680. Madrid: Cátedra.

Petrarca, Francesco. 1989. Cancionero. ed. Jacobo Cortines. Madrid: Cátedra. 2 vol.

Prieto, Antonio. 1984 y 1987. La poesía española del siglo XVI. Madrid: Cátedra. 2 vol.

Riquer, Martln de. 1983. Los trovadores. Historia literaria y textos. Barcelona: Ariel, 3 vol.

Rougemont, Denis de. 1984. El amor y Occidente. Barcelona: Kairós. Ja ed. 1979.

Salvador Miguel, Nicasio. 1977. La poesía cancioneril. El Cancionero de Estúnigga. Madrid: Alhambra.

Santillana, Marqués de. 1982. Poesias completas, I. ed. Manuel Durán. Madrid: Clásicos Castalia. $n^{\circ} 64$.

Savona, Eugenio. 1973. Repertorio tematico del Dolce Stil Nuovo. Bari: Adriatica Editrice.

Serés, Guillermo. 1994. "El concepto de Fantasia, desde el estética clásica a la dieciochesca" Anales de Literatura Española, X. pp. 207-236

Tumer, John H. 1977. The Myth of Icarus in Spanish Renaissance Poetry. London. Tamesis Books.

Villamediana, Conde de. 1980. Obras. ed. Juan Mauel Rozas. Madrid: Clásicos Catalia. n8.

Whinon, Keith. 1981. La poesia amatoria de la época de los Reyes Católicos. Durham: University of Durham 